Transportation Research Forum

Analysis of Traveler Characteristics by Mode Choice in HOT Corridors

Author(s): Mark W. Burris and Carlos F. Figueroa

Source: Journal of the Transportation Research Forum, Vol. 45, No. 2 (Summer 2006), pp. 103-117

Published by: Transportation Research Forum

Stable URL: http://www.trforum.org/journal

The Transportation Research Forum, founded in 1958, is an independent, nonprofit organization of transportation professionals who conduct, use, and benefit from research. Its purpose is to provide an impartial meeting ground for carriers, shippers, government officials, consultants, university researchers, suppliers, and others seeking exchange of information and ideas related to both passenger and freight transportation. More information on the Transportation Research Forum can be found on the Web at www.trforum.org. 


\title{
Analysis of Traveler Characteristics by Mode Choice in HOT Corridors
}

\author{
by Mark W. Burris and Carlos F. Figueroa
}

This research examined travelers who have a vast array of travel options, including some rather unique ones: HOV3 + in an HOV lane, HOV2 + in an HOV lane off-peak, HOV2 plus a \$2.00 toll in an HOV lane during the peak, and casual carpooling (slugging). Travelers using all these modes were surveyed in 2003, and significant differences between the groups of travelers were observed, providing some understanding of travel behavior when faced with these travel options. In the study, particular effort was spent on examining the characteristics of travelers who choose to travel as HOV2 carpools during peak periods and pay a \$2.00 toll. This group of travelers was found to contain significantly more well-educated females with high household incomes on school related trips. The proximity of private schools near the terminus of the HOV lane probably contributed significantly to this result. Due to the array of mode choices available to these travelers, surveying all these groups was challenging and, therefore, the methodology employed in survey development and administration is also detailed in this paper.

\section{INTRODUCTION}

Transportation planners are faced with the difficult task of providing decision makers with an array of options designed to improve mobility (Meyer and Miller 2001). In addition, planners attempt to predict the impact of these various options on the mobility and social welfare of travelers. Due to increasingly tight transportation budgets and significant congestion, these options are used more frequently and include tolls—both in the form of traditional, flat-rate tolls and value pricing options. However, the limited number of operational value pricing projects (Burris and Pendyala 2002) negatively impacts the ability to predict how drivers react to (and therefore value) these value pricing options. Without this knowledge, it is difficult to predict the mobility and social welfare impacts of value pricing and, in turn, difficult to recommend such projects.

There has been a wealth of theoretical analysis of the impact of many different forms of value pricing, both on the mobility (Dahlgren 2002, Verhoef and Small 2004, Small 1992) and the social welfare (Glazer and Niskanen 2000, Mayet and Hansen 2000, Viegas 2001, Ferrari 2002) of travelers. These analyses have been beneficial in convincing some localities to try innovative value pricing projects. In turn, these few operational projects have added to the theoretical knowledge base with some empirical results (Supernak et al. 2003a, Supernak et al. 2003b, Yan et al. 2002, Burris and Stockton 2004, Burris et al. 2004). These early projects continue to provide important real-world data, and the research detailed here includes results from driver surveys from a pair of high-occupancy/toll (HOT) lanes in Houston, Texas. Due to the complexity involved in collecting data from these projects, the data collection procedures are discussed in depth.

The following section provides the history of the two HOT lanes examined in this research. Next, the data collection and analysis processes are discussed. Then the results of the statistical analysis and the estimation of a discrete choice model are shown. The paper then ends with a conclusion section.

\section{HOT LANE BACKGROUND}

In 1984, when the Katy high-occupancy vehicle (HOV) lane opened, only registered vanpools and transit buses could use the lane (see Figure 1). To more effectively use the lane, vehicles with two 
or more occupants (HOV2+) were soon allowed. However, the lane became congested during the peak traffic periods, and in 1988, the Metropolitan Transit Authority of Harris County (Houston METRO) and the Texas Department of Transportation (TxDOT) decided to restrict usage of the lane to vehicles with three or more occupants (HOV3+) during the peak traffic periods between 6:45 a.m. and 8:00 a.m. and also between 5:00 p.m. and 6:00 p.m. This restriction was also implemented on the Northwest Freeway (US 290) during the morning peak period from 6:45 a.m. to 8:00 a.m. in 1999 (Turnbull 2003).

Figure 1: Houston Area HOV Lanes

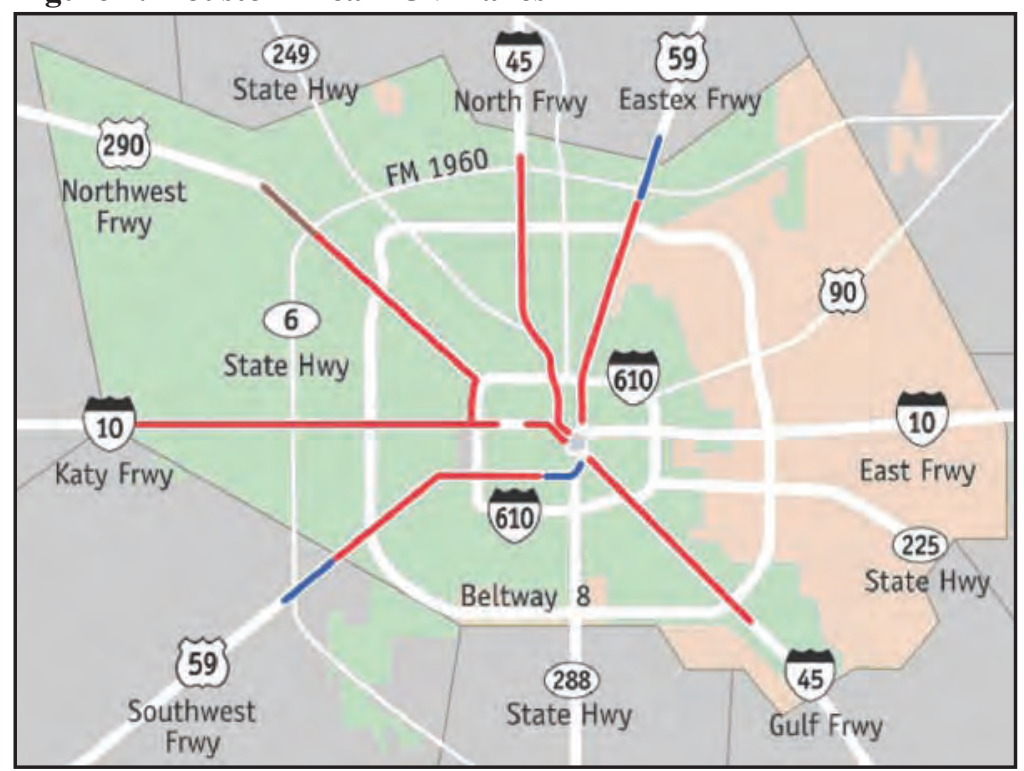

(Source: http://www.ridemetro.org/TransportationServices/Carpool_Vanpool_Services/HOV_system.asp)

Raising the occupancy restriction from HOV2+ to HOV3+ resulted in a considerable reduction in peak period traffic and, therefore, an increase in spare capacity in the HOV lanes (Burris and Stockton 2004). Houston METRO and TxDOT developed an innovative solution to this problem in 1998 by creating the QuickRide program where HOV2s could use the lanes for a $\$ 2.00$ toll during the peak periods, plus a $\$ 2.50$ monthly administrative fee. QuickRide benefits include: the ability to limit the demand for the HOV lane to an acceptable and desirable level, a more efficient use of the lane, and the generation of revenue to help pay for the program. With the implementation of this toll, this lane became a high-occupancy/toll lane or HOT lane. Travelers in these corridors now had many travel options, including: (1) driving alone in the main lanes, (2) carpooling in the main lanes, (3) using the Houston METRO buses, (4) casual carpooling in the HOV lanes (slugs), (5) regular carpooling in the HOV lanes, and (6) using the QuickRide program.

The QuickRide program has experienced a slow and steady increase in its usage since it began in 1998. However, there is still some available capacity that may be used to improve the utilization of the lanes and increase QuickRide participation. As an initial step toward increasing QuickRide participation, this research examined significant differences in the socioeconomic and commute characteristics of the six groups of travelers. In addition, the study found that a lack of public awareness may partially explain why QuickRide had not reached optimum usage.

Among QuickRide participants, previous studies found that the primary reason limiting additional usage of QuickRide was the difficulty, or disutility, of finding a passenger (Burris and Appiah 2004). A greater understanding of the disutility of carpooling-and the characteristics that are significantly different between travelers who carpool in the HOV lane for free (HOV3+), those who carpool and pay a toll (HOV2), and those who travel via other modes (SOV, transit, and 
slugs) — will help transportation planners understand the value different groups of travelers place on each option.

Additionally, knowing more about the different groups of travelers based on their mode selection can increase transportation planners' ability to achieve a balance between level of service, toll rate, and effective use of capacity of the HOV lanes. This knowledge will help predict the use of HOT lanes both in Houston and in cities contemplating the creation of HOT lanes. One way this is accomplished is through the estimation of a discrete mode choice model. Although it is unlikely this model can be directly transferable to other cities, it should provide planners some insight into HOT lane potential in their cities.

\section{RESEARCH METHODOLOGY}

\section{Data Collection}

The data analyzed in this research were collected in two separate surveys. The first survey was conducted in March 2003 and was mailed to all 1,459 people who were enrolled in the QuickRide program as of December 2002. A total of 93 surveys were returned by the post office due to incorrect addresses. Of the remaining 1,366 surveys, 525 were completed and returned on time for a response rate of 38.4\%. The survey included 36 questions regarding the respondent's most recent QuickRide trip, most recent non-QuickRide trip, typical use of QuickRide, feelings toward alternate QuickRide tolling scenarios, and socioeconomic characteristics. For a detailed analysis of this survey, see Burris and Appiah (2004).

The second set of data analyzed was obtained in a survey conducted in November 2003. Travelers in the QuickRide corridors who were using modes other than QuickRide were surveyed. To ensure all other modes were captured, surveys were distributed to travelers in the general purpose lanes, the HOV lanes, transit vehicles, and casual carpool (slug) lines. To distribute surveys to travelers in the general purpose and HOV lanes, the license plates of vehicles in these lanes were recorded approximately four weeks before the survey was mailed.

It was somewhat challenging to capture these license plates while maintaining a low profile. Due to some drivers' extremely negative reaction to being videotaped, video cameras were located on Katy and Northwest Freeway overpasses and recorded vehicles traveling in the freeways below. The cameras were positioned such that the majority of travelers being videotaped would not notice them (see Figure 2).

\section{Figure 2: Recording License Plates on Northwest Freeway}

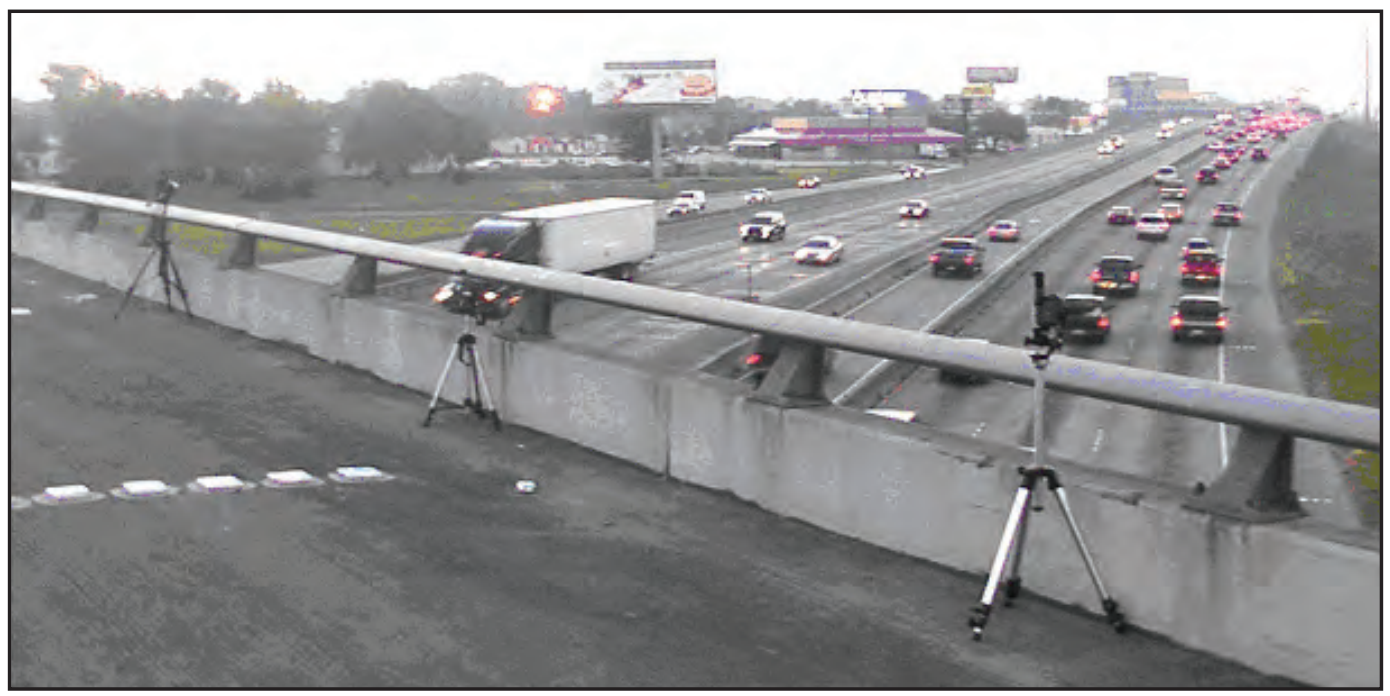


This configuration worked extremely well during periods in which traffic was congested and vehicles were traveling at low (less than $30 \mathrm{mph}$ ) speeds. However, at higher speeds, it was difficult to capture a vehicle's license plate so it could be read on video. Difficulties arose due to the speed of vehicles and angle of the video. In an ideal camera configuration, the camera would zoom in on a license plate so the plate covered $20 \%$ to $25 \%$ of the screen width without the vehicle behind it blocking the plate. When vehicles are traveling at speeds higher than $45 \mathrm{mph}$, the license plate may not remain in the video frame long enough to read the license plate. To compensate for this problem, it was possible to reduce the angle of the camera-videotaping vehicles farther away and increasing the zoom. This often resulted in the lead vehicle's license plate being blocked by a following vehicle. A steeper angle for the camera resulted in a plate that remained in the video frame for too short a time to read. After some practice the best angles for multiple speeds were determined, but in high-speed conditions with low light (e.g., just prior to the start of the morning rush hour) very few plates were captured regardless of how the camera was deployed. Alternatively, placing the cameras at freeway level would have offered a better video of license plates-but the added likelihood of negative reaction from drivers made this option unattractive.

It was also found that cameras that recorded a digital image provided relatively little advantage over a Hi8 camera with professional-grade playback equipment. Approximately 75 hours of license plate data were recorded. Anywhere from approximately 800 plates per hour of tape to 0 plates per hour could be identified when examined in the laboratory. In all, 19,260 plates were identified for an average of approximately 250 plates per hour of video. Next, 1,580 duplicate plates and a handful of QuickRide enrollee plates were removed. QuickRide enrollees were removed since they had been surveyed months before.

The remaining plate numbers were sent to the Texas Department of Public Safety (DPS), which provided names and addresses for all but 2,080 plates for which they had no records. In addition, 430 plates originated outside of Texas, and 1,220 were assigned to a business. This left slightly fewer than 14,000 names and addresses to which surveys could be mailed. Of those, approximately 1,150 were returned by the post office due to wrong addresses. Therefore, approximately $66.5 \%$ $(12,800 / 19,260)$ of the original license plates provided potential survey respondents, for an average of 170 plates per hour of videotape. The plates were then categorized as to the time of day (morning peak, morning off-peak, evening peak, or evening off-peak), the freeway (Katy or Northwest), and the lane (general purpose or HOV) where they were recorded. This resulted in 16 categories of license plates. These plates, collected four weeks before the survey, were supplemented with 2,847 plates collected in the HOV lanes two months before the survey (the plates were collected for an earlier effort involving mailing warning letters to HOV violators but were never used). A minimum of 850 plates were available in each of the 16 categories. In the general purpose lanes, during peak periods, a greater number of plates (between 1,300 and 1,500) were available.

The freeway (Katy or Northwest) and time of day (morning or afternoon) when a vehicle was observed dictated which version of the survey was mailed to the registered owner of that vehicle. In this manner questions could specify a roadway and time of day. For example: "Please tell us about your most recent morning trip on Katy Freeway traveling toward downtown Houston.” This was done to reduce potential respondent confusion that might occur with a completely generic survey. Note that the survey never mentioned that the respondent was observed on any roadway at any time. Also, the survey did not change based on whether the vehicle was observed in the HOV or general purpose lanes. The respondents indicated which lane they used as part of the survey. The surveys also varied by the stated preference questions asked. This process is described in detail in the next section. Since the surveys were anonymous, there was no way to match the license plate to the returned survey.

Respondents had the option of replying online or by filling out the survey and mailing it back in a postage-paid return envelope supplied with the survey. Responses postmarked or submitted online within four weeks of the date the surveys were mailed were entered into a database. Surveys 
returned after that date were not entered since traffic conditions were likely changing due to the approach of the Christmas holiday season. Response rates were acceptable, as shown in Table 1.

Table 1: Survey Distributions and Response Rates

\begin{tabular}{cccccc}
\hline Target Market & $\begin{array}{c}\text { Approximate } \\
\text { \# Travelers in } \\
\text { Target Market }\end{array}$ & $\begin{array}{c}\text { Surveys } \\
\text { Distributed }\end{array}$ & $\begin{array}{c}\text { Surveys } \\
\text { Returned } \\
\text { (Mail) }\end{array}$ & $\begin{array}{c}\text { Surveys } \\
\text { Returned } \\
\text { (Web) }\end{array}$ & $\begin{array}{c}\text { Survey } \\
\text { Response } \\
\text { Rate (\%) }\end{array}$ \\
\hline $\begin{array}{c}\text { General Purpose } \\
\text { Lanes } \\
\text { HOV Lane } \\
\text { (Non-QuickRide) }\end{array}$ & Unknown ${ }^{1}$ & 8,670 & 1,441 & 680 & 24.4 \\
Transit ${ }^{2}$ (Onboard) & 13,500 & 5,330 & 490 & 94 & 11.0 \\
Casual Carpool & 5,350 & 700 & 546 & 38 & 83.4 \\
QuickRide & 1,459 & 540 & 200 & 16 & 40.0 \\
\hline Total & 56,389 & 16,606 & 3,202 & 828 & 24.3
\end{tabular}

1. Each roadway had an annual average daily traffic volume in excess of 200,000 vehicles.

2. For transit travelers, the majority of completed surveys were handed to a surveyor on the bus at the end of the respondents' trips. Transit riders were also given a postage-paid return address envelope to mail the survey back if they chose to.

\section{Stated Preference Questions}

Base surveys that contained minor word changes were developed to make the survey easier for the respondents to answer, as discussed in the previous section. The matrix of base surveys is shown in Table 2. One set was developed for Katy Freeway travelers and another for Northwest Freeway travelers (except in the case of casual carpool passengers, where three sets were developed for the three locations in which casual carpooling occurs). Therefore, a total of 23 different base surveys were created.

Table 2: Matrix of Base Surveys

\begin{tabular}{ccccc}
\hline Mode & AM Peak & PM Peak & AM Off-Peak & PM Off-Peak \\
\hline $\begin{array}{c}\text { Automobile on } \\
\text { Lenal Purpose } \\
\text { Lane }\end{array}$ & $\begin{array}{c}\text { Katy } \\
\text { Northwest }\end{array}$ & $\begin{array}{c}\text { Katy } \\
\text { Northwest }\end{array}$ & $\begin{array}{c}\text { Katy } \\
\text { Northwest }\end{array}$ & $\begin{array}{c}\text { Katy } \\
\text { Northwest }\end{array}$ \\
\hline Transit & $\begin{array}{c}\text { Katy } \\
\text { Northwest }\end{array}$ & $\begin{array}{c}\text { Katy } \\
\text { Northwest }\end{array}$ & & \\
& $\begin{array}{c}\text { Addicks, } \\
\text { Northwest Station, } \\
\text { and Kingsland } \\
\text { Park-and-Ride } \\
\text { Lasual Carpool }\end{array}$ & & & \\
& $\begin{array}{c}\text { Katy } \\
\text { Northwest }\end{array}$ & $\begin{array}{c}\text { Katy } \\
\text { Northwest }\end{array}$ & $\begin{array}{c}\text { Katy } \\
\text { Northwest }\end{array}$ & $\begin{array}{c}\text { Katy } \\
\text { Northwest }\end{array}$ \\
\hline $\begin{array}{c}\text { Automobile on } \\
\text { HOV Lane }\end{array}$ & &
\end{tabular}


The next step was to develop the stated preference portion of the survey. Based on focus group responses, literature reviews, and experience with HOT lanes, it was clear that three main factors influenced travelers' choice of mode: (1) travel time, (2) travel cost, and (3) travel time reliability (Lam and Small 2001, Bates et al. 2001, Kazimi 2000, Small et al. 1999). Initially, stated preference questions were designed with multiple levels of these three factors with choices between the following modes of travel:

1. single-occupant vehicle (SOV) in the general purpose lanes during both the peak and offpeak periods,

2. two-person carpool in the HOV lane during the peak period (the current QuickRide operation),

3. carpool in the main lanes during the peak period,

4. single-occupant vehicle in the HOV lane during both the peak and off-peak periods (does not currently exist),

5. transit rider during both the peak and off-peak periods,

6. two-person carpool in the HOV lane during the off-peak period,

7. three-person carpool in the HOV lane during the peak period, and

8. casual carpool in the HOV lane during the peak period.

From the pilot survey responses, it was clear the travel choice options were too complex with three main factors per choice. Therefore, the stated preference questions were simplified to contain only travel time and toll rate factors.

Next, the toll rate and travel time levels were developed. For the entire array of choices, three factors had three levels, and seven factors had two levels $\left(3^{3} 2^{7}\right)$. To capture the majority of the main effects between variables, an orthogonal array was developed to facilitate selection of levels for individual questions. The fractional factorial design required 36 questions to cover the main effects (Lorenzen and Anderson 1993). Since each respondent would be asked four stated preference questions, nine different survey versions were required for each base survey. This resulted in 207 different surveys mailed to Katy and Northwest Freeway travelers. The levels of the factors were based on realistic toll levels and travel times. Responses were obtained from respondents from almost all versions of the survey. Only nine versions of the survey (out of 207) did not have any responses.

\section{DATA ANALYSIS}

The two data sets were combined, and erroneous responses were removed. The respondents were then grouped according to their mode choice. This was the primary dependant variable and consisted of six options: people who drove alone in the main lanes, people who carpooled in the main lanes, people who traveled by bus, people who casual carpooled (they carpooled with strangers) in the HOV lane, people who carpooled with people they knew in the HOV lane, and QuickRide users.

Eleven responses could not be classified into any of these six alternatives. These respondents indicated that they traveled in the main lanes but failed to answer if they traveled alone or with passengers. These 11 responses were removed from the data set, leaving 4,005 responses for analysis.

To begin, standard statistical analyses were used to determine any significant differences between the different groups of travelers (by mode choice) (see Table 3). To determine if socioeconomic and commute differences between the groups were statistically significant $(p=0.05)$, the Chi-squared test was used on nominal data (e.g., household type, occupation), the Kruskal-Wallis test was used on ordinal data (e.g., age, income), and ANOVA was performed on continuous data (e.g., trips per week, persons in household).

Additionally, the explanatory variables were examined for correlations. Two variables that showed strong correlation could not be used together in the discrete choice models developed to predict mode choice. Also QuickRide responses were weighted to more accurately reflect their true 
level of QuickRide participation (Burris and Appiah 2004), and all surveys were weighted by mode to reflect the numbers of travelers using each mode on the freeways.

The discrete choice (logit) model was estimated using standard multinomial logit modeling techniques (Ben-Akiva and Lerman 1985, Train 2003). Since QuickRide was such a unique mode of travel, the logit model estimated in this research focused on the characteristics of travelers' who used QuickRide versus the other modes. This was accomplished by interacting many of the variables used in the model with a QuickRide dummy variable (equal to 1 if the traveler's mode was QuickRide and equal to 0 if the mode was other than QuickRide.) Thus, many variables only entered the model when the traveler used QuickRide. This model allowed for expansion of the statistical analysis discussed above by accounting for interactions among the variables and gaining insight into which characteristics were most influential in estimating a traveler's choice to use QuickRide.

\section{RESULTS}

The results of the statistical analysis can be found in Table 3. The discussion below highlights a few of the significant differences, with a focus on QuickRide participants.

When asked about their trip purpose, $79.2 \%$ of the respondents were commuting. There were significant differences between the six groups of respondents (grouped by mode choice) in each of the five trip purposes (commuting, recreation, work, school and other). Respondents choosing to casual carpool (slug) were more likely to be commuting (96.3\% commuted) and less likely to be traveling for school or other purposes (both $0 \%$ ). Also, transit riders were more likely to be traveling for commute purposes (93.2\%). QuickRide participants were less likely to be on a commute trip and significantly more likely to be on a school trip.

There was a difference between the average travel times of the six groups. The QuickRide participants experienced the shortest travel time with an average of 46.4 minutes per trip. The slugging participants had the longest travel times, with an average of 60.33 minutes. For slugs to have long commute times was not surprising since each slug pick-up location was far from downtown Houston, plus slugging required mode transfers. Slugs first had to drive to a park-andride lot, walk to the slug line, wait for a ride, travel in the HOV lane, and then walk to their final destination.

The slugs had a significantly higher number of weekly trips in this corridor, 9.68, than any other group. In second place were the regular carpoolers with 9.48 trips per week, and in third place were the transit riders with 9.32 trips per week. None of these results are surprising due to the high percentage of daily travelers (commuters) in these groups.

Regular carpoolers had a significantly higher number of persons per household with an average of 3.22 persons per household. The group of people who drive alone in the main lanes had the lowest average number of people living in the household, 2.98. When examining the groups who carpooled, the carpool passengers were predominantly (over 60\% for each group) a family member. Thus, it was not surprising that travelers in larger households were more likely to carpool.

Approximately 58\% of all the respondents answered that they knew about the QuickRide program before the survey. Among non-QuickRide users, slugging participants were more likely (64.8) than others to have heard about QuickRide before the survey. People who knew about QuickRide were asked how they learned about it. The largest percentage, 35.7\%, learned about the program from their families or friends, and just $1.9 \%$ of all participants learned about the program on the bus. Approximately $40 \%$ of QuickRide participants heard about the program from family members or friends. Approximately 36\% of slugging participants heard about the program by methods other than the ones included in the survey. QuickRide has not been extensively promoted, as evidenced by the very low percentage of respondents who heard of it from television, radio, mail, on the bus, a family member, or a friend (see Table 3 ).

Among the respondents who traveled with someone, the most common travel companion (39.3\%) was an adult family member, while the least common (2.9\%) was a neighbor. In the QuickRide 


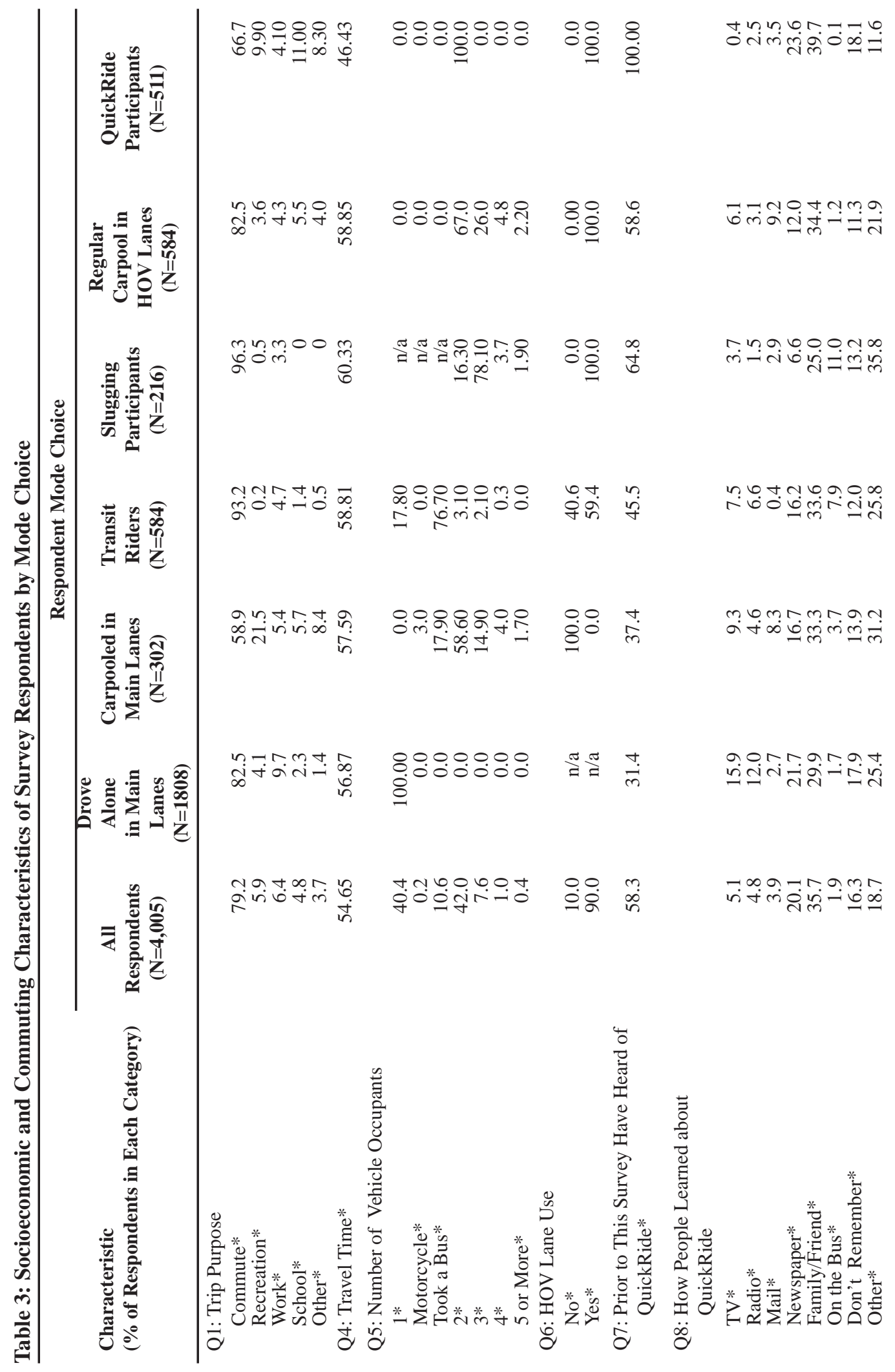


Traveler Characteristics

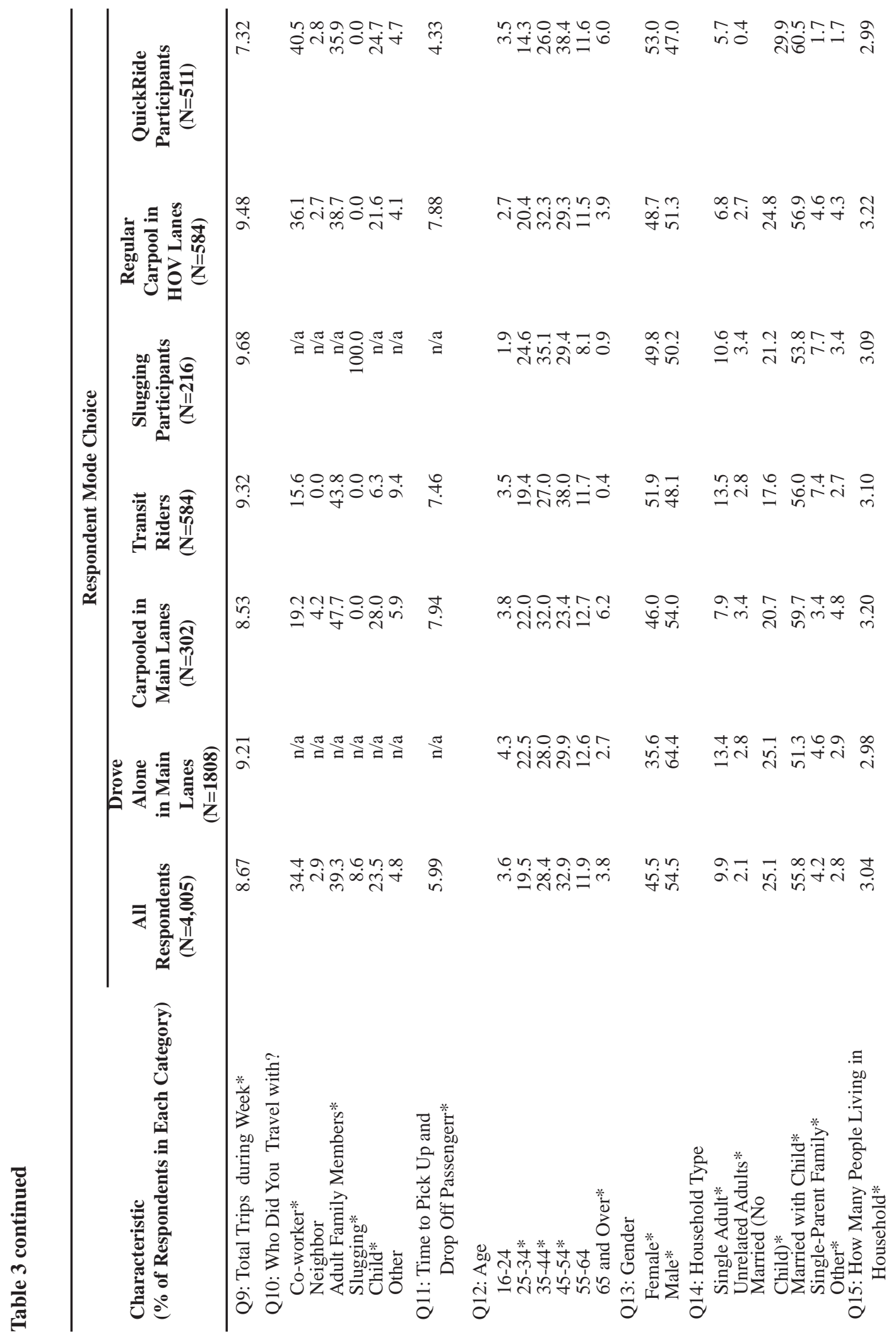




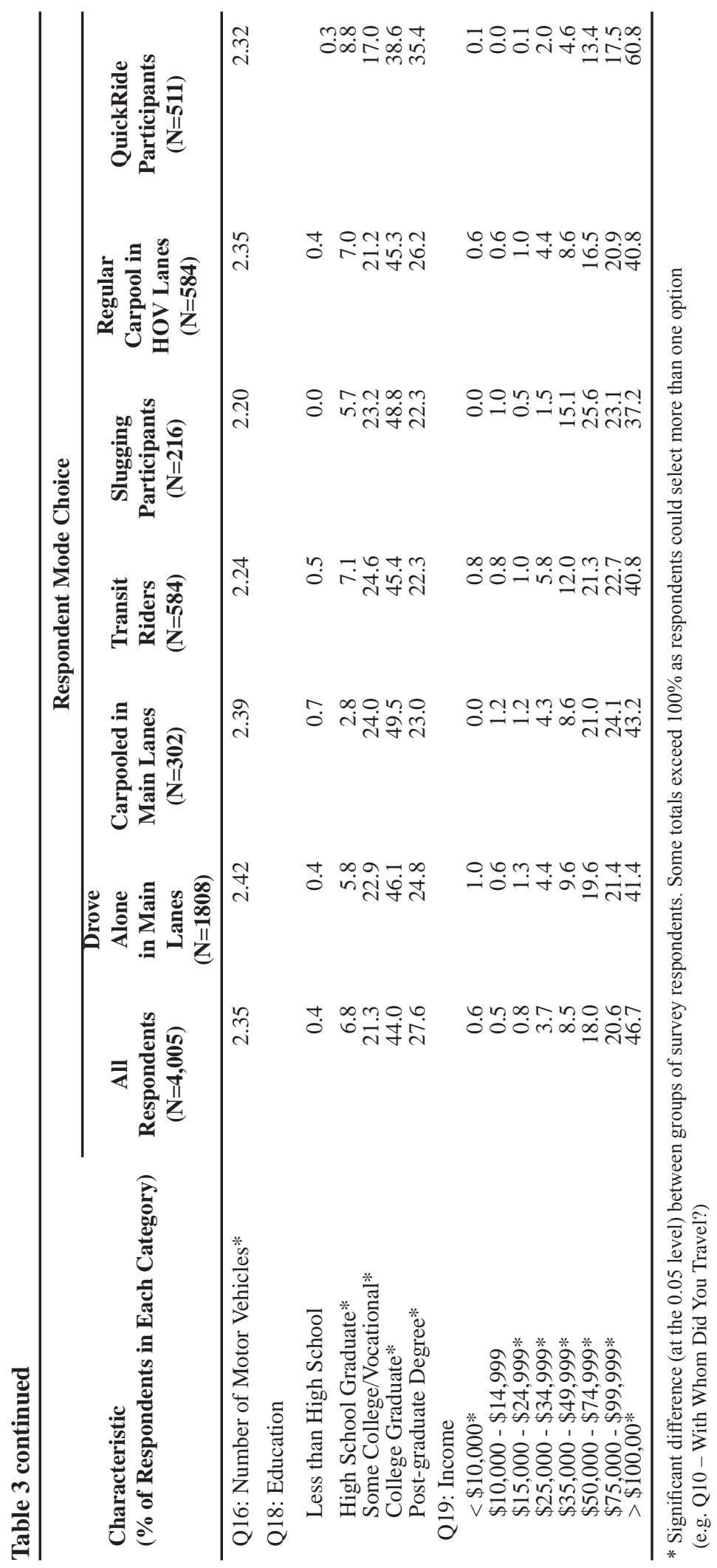


travel option, $40.5 \%$ of the respondents indicated they traveled with a co-worker, $35.9 \%$ indicated they traveled with an adult family member, and $24.7 \%$ indicated they traveled with children. For regular carpoolers in the HOV lane, many traveled with an adult family member (38.7\%) or with a co-worker (36.1\%). Among all participants, 54.5\% were males and $45.5 \%$ were females. QuickRide participants and transit riders were significantly more likely to be female with more than half of both groups being female. Most other groups were fairly evenly split between the sexes, except driving alone in the main lanes, which was predominantly (64.4\%) male.

There were differences in household incomes between groups except for the annual income category of $\$ 10,000$ to $\$ 14,999$. In general, respondents traveling along these corridors had high household incomes with at least $60 \%$ having a household income greater than $\$ 75,000$ per year. In addition, all but one group had over $40 \%$ of their respondents having household incomes in excess of $\$ 100,000$ per year. QuickRide participants were significantly more likely to have incomes in excess of $\$ 100,000$ (60.8\%). The only other trend observed with respect to household income was that slugs had the most uniform distribution of household incomes.

\section{Specific Comparisons with Respect to QuickRide Participants}

QuickRide participants were significantly more likely to be on school trips (11.0\%) than any other group. This is an interesting result, and it will be explored further by examining those travelers. Travelers using QuickRide for a school trip were most frequently (76\%) traveling with a child, were married with children (81\%), were female (62\%), were between the ages of 45 to $54(60 \%)$, were well educated (21\% had some college while $69 \%$ did post graduate studies) and had an annual household income in excess of $\$ 100,000$ (79\%). This would indicate QuickRide is a convenient way for this group of travelers to take their children to school-which is not surprising as there are a couple schools near the inbound terminus of the HOT lanes, including private schools that do not offer transportation. Additionally, 92\% of the female drivers on a school related QuickRide trip were traveling with a child.

The average travel time for all respondents was 54.8 minutes, indicative of the long distances in congested traffic facing travelers on these freeways. The highest average travel time was 69.3 minutes and it was by people who selected trip purposes categorized as "other." Respondents who chose this category were also more likely than others to be older and traveling long distances. Based on written comments of the respondents, many of these travelers were seeking medical care, mainly at Houston's medical center, which attracts patients from long distances.

Respondents making school trips had the shortest average travel time of 50.4 minutes. This was due, in part, to QuickRide travelers having the shortest trip time of 46.4 minutes. Both of these short travel times can be partially attributed to the speed of picking up a single passenger. When using QuickRide only one passenger is needed, and that passenger was often (60.6\% of the time) someone in the same household. Other carpool formations included those with two or more passengers, requiring additional carpool formation time. The passenger pickup times for other carpools (both on the main lanes and on the HOV lanes) were very similar, with an average near 7.9 minutes. These times included waiting for the passengers and not just travel times, as all groups, including those who were only carpooling with people in the same house, indicated passenger pickup times up to 30 minutes.

Since travel is a derived demand, a traveler's mode choice is influenced by his or her reason for traveling. This analysis of QuickRide participants indicated that a sub-group (large enough to influence the characteristics of the entire group of QuickRide participants) used QuickRide for the convenience of taking their children to school. Often these participants were from wealthy households and their children attended private schools. Thus, the influence of travel purpose on HOT lane use was evident and this result is likely transferable to other locations considering HOT lanes similar to Houston's. Recall that in Houston's HOT lanes, HOV3+ travel free at all times while those using HOV2 travel free most times except the peak periods. Therefore, some QuickRide 
participants (those using HOV2 during the peak) were influenced by destinations near the termini of the lanes that required arrival/departure at specific times and multiple occupants (such as a school for children too young to drive themselves). Similar analyses of destinations near termini of potential HOT lanes should help planners anticipate demand for those lanes.

\section{Discrete Choice Model}

To further investigate the difference between QuickRide participants and travelers using other mode choices, a multinomial logit model was estimated. The model predicted respondents' actual mode use (revealed preference) using their socioeconomic and commute characteristics as reported in the surveys. The model focused on QuickRide mode use, so a total of 2066 surveys (of the 4005 surveys) where the traveler indicated no prior knowledge of the QuickRide program were removed from the sample. This was done to build a model that more accurately reflected travelers' choices based on the knowledge that QuickRide was an option.

Many models were tested using traveler and trip characteristics obtained from the survey. The utilities of five of the six travel modes were estimated relative to that of a single occupant vehicle on the main lanes, which was the base mode with a utility of 0 . The mode choice with the highest utility for a traveler was the most likely mode choice for that traveler.

The characteristics of the mode itself, such as travel time and occupants required, were felt to be implicitly included in the traveler's choice of that mode and therefore were not included in the models. The final model (see Table 4) had both the highest adjusted rho squared value and the highest percentage of mode choices estimated correctly. Unfortunately, due to the similarity of several of the modes, both the adjusted RHO squared value and percent correct values were relatively low. For example, on any given day a slug may take the bus or vice versa, depending on the wait that day. Similarly, there were many travelers who traveled in HOV3 carpools, but on occasion the third person was unavailable and they traveled as an HOV2 carpool on the main lanes or QuickRide users. This modal flexibility made estimating a model to predict travelers' mode use based on their socioeconomic characteristics less accurate.

The model results confirmed the statistical analysis described in the previous section. Travelers using QuickRide for their trips were significantly more likely to be over 65 years old, have a postgraduate degree, have a household income greater than $\$ 100,000$ per year, and be on a school-related trip. They were significantly less likely to be male, between 25 to 34 years old, and living alone.

\section{CONCLUSIONS}

The use of value pricing to both manage demand for transportation facilities and generate revenue is increasingly examined by transportation agencies as a viable alternative. However, the number of operational projects, and therefore empirical results, is limited.

This research examined both the method used to obtain traveler data on a pair of HOT lanes and an analysis of that data. Travelers along the two HOT lane corridors in Houston had an array of travel options available to them. Therefore, it was necessary to develop over 200 versions of combined revealed and stated preference surveys to adequately capture traveler behavior from all groups of travelers. The survey data were analyzed to determine significant differences between groups of travelers, with a focus on those travelers selecting QuickRide - the value pricing option. Further analysis using a discrete choice model confirmed that QuickRide participants were more likely to be over 65 years old, have a post-graduate degree, have a household income greater than $\$ 100,000$ per year, and be on a trip to school. They were significantly less likely to be male, between 25 to 34 years old, and living alone. 
Table 4: Model of Mode Choice-Focused on QuickRide Use

\begin{tabular}{lccc}
\hline Variable Name & Coefficient & t-statistic & Prob. \\
\hline Mode Specific Coefficients: & & & \\
QuickRide & -3.06 & -48.03 & 0.00 \\
Carpool in HOV & -1.68 & -99.72 & 0.00 \\
Slugging & -4.11 & -78.07 & 0.00 \\
Transit & -2.45 & -103.34 & 0.00 \\
Carpool in Main Lanes & -1.61 & -98.43 & 0.00 \\
QR*Age 65 or Older & 1.64 & 13.13 & 0.00 \\
QR*Household Type Is Single Adult & -1.24 & -7.41 & 0.00 \\
QR*Post-graduate Degree & 0.49 & 7.16 & 0.00 \\
QR*Household Income $>$ \$100,000 & 0.51 & 7.79 & 0.00 \\
QR*School Trip & 1.78 & 16.17 & 0.00 \\
QR*Male & -0.80 & -11.94 & 0.00 \\
QR*Age 25 to 34 & -0.62 & -6.53 & 0.00 \\
& & & \\
N & & 1939 & \\
Log Likelihood & & -37861 & \\
Restricted Log Likelihood & & -61481 & \\
Adjusted Rho Squared & & 0.383 & \\
\hline Percent Correct (Note Each Mode Predicted between 5 and & 24 & \\
35\% Correct) & & & \\
\hline
\end{tabular}

$\mathrm{QR}$ = a dummy variable, equal to 1 if mode used was QuickRide, 0 otherwise.

Base mode was SOV on the main lanes.

\section{References}

Bates, J., J. Polak, P. Jones, and A. Cook. "The Valuation of Reliability for Personal Travel.” Transportation Research 37 (E), (2001): 191-229.

Ben-Akiva, M. and S. R. Lerman. Discrete Choice Analysis: Theory and Application to Travel Demand. MIT Press, Cambridge, Massachusetts, 1985.

Burris, M. W. and R. M. Pendyala. "Discrete Choice Models of Traveler Participation in Differential Time of Day Pricing Programs.” Transport Policy 9 (3), (2002): 241-251.

Burris, M. and W. Stockton. “HOT Lanes in Houston-Six Years of Experience.” Journal of Public Transportation 7 (3), (2004): 1-21.

Burris, M. W. and J. Appiah. “An Examination of Houston’s QuickRide Participants by Frequency of QuickRide Usage.” Journal of the Transportation Research Board No.1864, (2004): 22-30.

Burris, M. W., K. K. Konduru, and C. R. Swenson. "Long-Run Changes in Driver Behavior Due to Variable Tolls.” Journal of the Transportation Research Board No. 1864, (2004): 78-85.

Dahlgren, J. “High-Occupancy/Toll Lanes: Where Should They Be Implemented?” Transportation Research, Part A: Policy and Practice 36 (3), (2002): 239-255.

Ferrari, P. "Road Network Toll Pricing and Social Welfare.” Transportation Research 36B, (2002): 471-483. 
Traveler Characteristics

Glazer, A. and E. Niskanen. "Which Consumers Benefit from Congestion Tolls?” Journal of Transport Economics and Policy 34 (1), (2000): 43-53.

Kazimi, C. "Willingness-to-Pay to Reduce Commute Time and Its Variance: Evidence from the San Diego I-15 Congestion Pricing Project.” Transportation Research Board 79th Annual Meeting, Washington, D.C., 2000.

Lam, T. C. and K. A. Small. "The Value of Time and Reliability: Measurement from a Value Pricing Experiment.” Transportation Research 37 (E), (2001): 231-251.

Lorenzen, T. J. and V. L. Anderson. Design of Experiments: A No-Name Approach. Marcel Dekker, Inc., New York, 1993.

Mayet, J. and M. Hansen. "Congestion Pricing with Continuously Distributed Values of Time.” Journal of Transport Economics and Policy 34 (3), (2000): 360-369.

Meyer, M. D. and E. J. Miller. Urban Transportation Planning: A Decision Oriented Approach, second ed. McGraw Hill, New York, 2001.

Small, K. A. Urban Transportation Economics. Harwood Academic Publishers GmbH, Great Britain, 1992.

Small, K. A., R. Noland, X. Chu, and D. Lewis. Valuation of Travel-Time Savings and Predictability in Congested Conditions for Highway User-Cost Estimation. National Academy Press, Washington, D.C., 1999.

Supernak, J., D. Steffey, and C. Kaschade. "Dynamic Value Pricing as Instrument for Better Utilization of High-Occupancy Toll Lanes: San Diego I-15 Case.” Transportation Research Record No. 1839, (2003a): 55-64.

Supernak, J., D. Steffey, and C. Kaschade. "Dynamic Value Pricing on I-15 San Diego: Impact on Travel Time and Its Reliability.” Transportation Research Board 82nd Annual Meeting, Washington, D.C., 2003b.

Train, K. Discrete Choice Methods with Simulation. Cambridge University Press. Cambridge, United Kingdom. 2003.

Turnbull, K. F. Houston Managed Lanes Case Study: The Evolution of the Houston HOV System. U.S. Department of Transportation, Federal Highway Administration, Washington, D.C., 2003.

Verhoef, E. T. and K. A. Small. "Product Differentiation on Roads: Constrained Congestion Pricing with Heterogeneous Users.” Journal of Transport Economics and Policy 38 (1), (2004): 127-156.

Viegas, J. M. "Making Urban Road Pricing Acceptable and Effective: Searching for Quality and Equity in Urban Mobility.” Journal of Transport Policy 8, (2001): 289-294.

Yan, J., K. Small, and E. Sullivan. "Choice Models of Route, Occupancy, and Time of Day with Value-Priced Tolls.” Transportation Research Record No. 1812, (2002): 69-77.

\section{Acknowledgments}

The authors would like to thank the Federal Highway Administration (FHWA), the Texas Department of Transportation, and Houston METRO for the implementation and support of the QuickRide project and the funding used to collect the data analyzed in this research. The authors would also like to thank the Dwight Look College of Engineering and the Department of Civil Engineering at Texas A\&M University for the Undergraduate Summer Research Grant Program that funded the student working on this analysis. Finally, the authors would like to thank the journal editors and two anonymous reviewers for their comments and suggestions which helped to improve this paper. However, any errors or omissions are solely the responsibility of the authors. 
Dr. Mark W. Burris is an assistant professor in the Department of Civil Engineering at Texas A\&M University, and an assistant research scientist at the Texas Transportation Institute. Dr. Burris's primary area of interest is congestion (or value) pricing. He has been, and continues to be, involved in many projects in this area. He has primarily served in an evaluation and monitoring role for the (1) Houston Value Pricing Project, (2) Lee County Variable Pricing Pilot Project, (3) Queue Jump Value Pricing Project, (4) Fort Myers Beach Cordon Toll Study and (5) Traveler Credit Based Pricing.

Prior to joining Texas A\&M in August 2001, he was a senior research associate at the Center for Urban Transportation Research (CUTR) in Tampa, Florida. Dr. Burris is a member of the American Society of Civil Engineers, the Institute of Transportation Engineers, and the Transportation Research Board's committees on Transportation Economics and Congestion Pricing.

Carlos F. Figueroa is currently attending the University of Puerto Rico at Mayagüez. In the summer of 2004, he worked with the Texas Transportation Institute at Texas A\&M University as part of an undergraduate summer internship, where he researched Houston's value pricing project: HOV/HOT lanes. From February 2005 to August 2005, he worked with the U.S. Department of Transportation, Federal Highway Administration (FHWA), and Puerto Rico Division Office as part of a COOP Program, where he dealt with inspection and contract administration of federal aid highway projects.

Carlos is the president of the Institute of Transportation Engineers (ITE) Student Chapter in the Department of Civil Engineering and Surveying at the University of Puerto Rico at Mayagüez, and he is part of the Civil Engineering Honor Roll at the University of Puerto Rico at Mayagüez. He will graduate in May 2006 with a Bachelor of Science degree in civil engineering from the University of Puerto Rico at Mayagüez, and will move to Atlanta, Georgia, in July 2006 to work with the Federal Highway Administration at the Georgia Division. 